\title{
El patrimonio intangible de la arquitectura tradicional: un recurso en la lucha contra el cambio climático
}

\author{
Mónica Alcindor | Escola Superior Gallaecia, Portugal \\ URL de la contribución <www.iaph.es/revistaph/index.php/revistaph/article/view/4970>
}

Uno de los principales retos al que se enfrenta la sociedad en su conjunto es el cambio climático. Los motivos que han creado esta situación son múltiples, pero de lo que no hay duda es de que la actividad humana tiene una gran influencia en el mismo, basada principalmente en la quema de combustible fósil, la tala de selvas tropicales, así como una sobreexplotación del ganado.

El registro de datos termométricos se inició en 1850 y desde esa fecha se ha podido comprobar cómo desde mediados del siglo XX el aumento de las temperaturas ha sido el patrón establecido, con un incremento de la concentración de $\mathrm{CO}_{2}$ del $40 \%$. Consecuencia, con toda probabilidad, de la actividad humana promovida por la expansión de la Revolución Industrial a mediados del siglo XIX (Foer 2019).

Actualmente el planeta únicamente puede soportar una cantidad determinada de incremento de temperatura antes de que los bucles, es decir, las cadenas de consecuencias, se retroactiven y den paso a un cambio climático desbocado. Por todo ello en el Acuerdo de París adoptado en la Conferencia sobre el Clima de París en 2015 se estableció como objetivo mantener el calentamiento global por debajo de los $2^{\circ} \mathrm{C}$.

Para conseguir este objetivo hace falta un esfuerzo colectivo en muchas áreas de la actividad humana con el fin de reducir las emisiones de carbono a cero. Cada sector debe innovar y cooperar en busca del cumplimiento de este objetivo.

Desde el área de la edificación las emisiones de carbono representan un $6 \%$ del total de las emisiones anuales de gases con efecto invernadero, por lo tanto es importante asumir el reto necesariamente desde esta activi- dad. Pero para conseguirlo no hace falta reinventar la construcción, sino "desinventarla", es decir, el futuro de la construcción necesita parecerse al pasado.

Las formas de vida introducidas después de la Revolución Industrial arrasaron de manera sin precedentes todas las modalidades tradicionales del orden social. Tanto en extensión como en intensidad, las transformaciones que ha acarreado han sido profundas (Giddens 2011). Los sistemas nacidos de la Revolución Industrial encajan perfectamente en un medio cultural en el que se priorizan la regulación administrativa, los negocios y la conveniencia técnica, aunque desgraciadamente sin atender a un equilibrio ecológico. Estos sistemas han favorecido la desaparición de técnicas de base social tradicionales, elaboradas mediante un método a menudo polifuncional, y que partían de un enfoque integrado y estrictamente ligado a una concepción del mundo fundada en la cuidadosa gestión de los recursos locales (Laureano 1999).

Desde el ámbito de la arquitectura se hace necesario realizar un balance serio y reorientar la investigación científica y técnica en función de las nuevas aspiraciones. Uno de los pasos previos sería el reconocimiento y la valoración de aquellas técnicas locales que alguna vez en el pasado proporcionaron soberanía tecnológica con una cuidadosa gestión de los recursos y bajas emisiones de $\mathrm{CO}_{2}$.

Por lo tanto, un ejercicio fundamental a realizar es saber reconocer de nuestro pasado todo aquello que el "progreso" ha dejado atrás pero que sería de gran interés recuperar y "reproponer" en futuras actuaciones, ya que tal como pronunció Claude Lévi-Strauss en su legendario ensayo Raza y Cultura: 


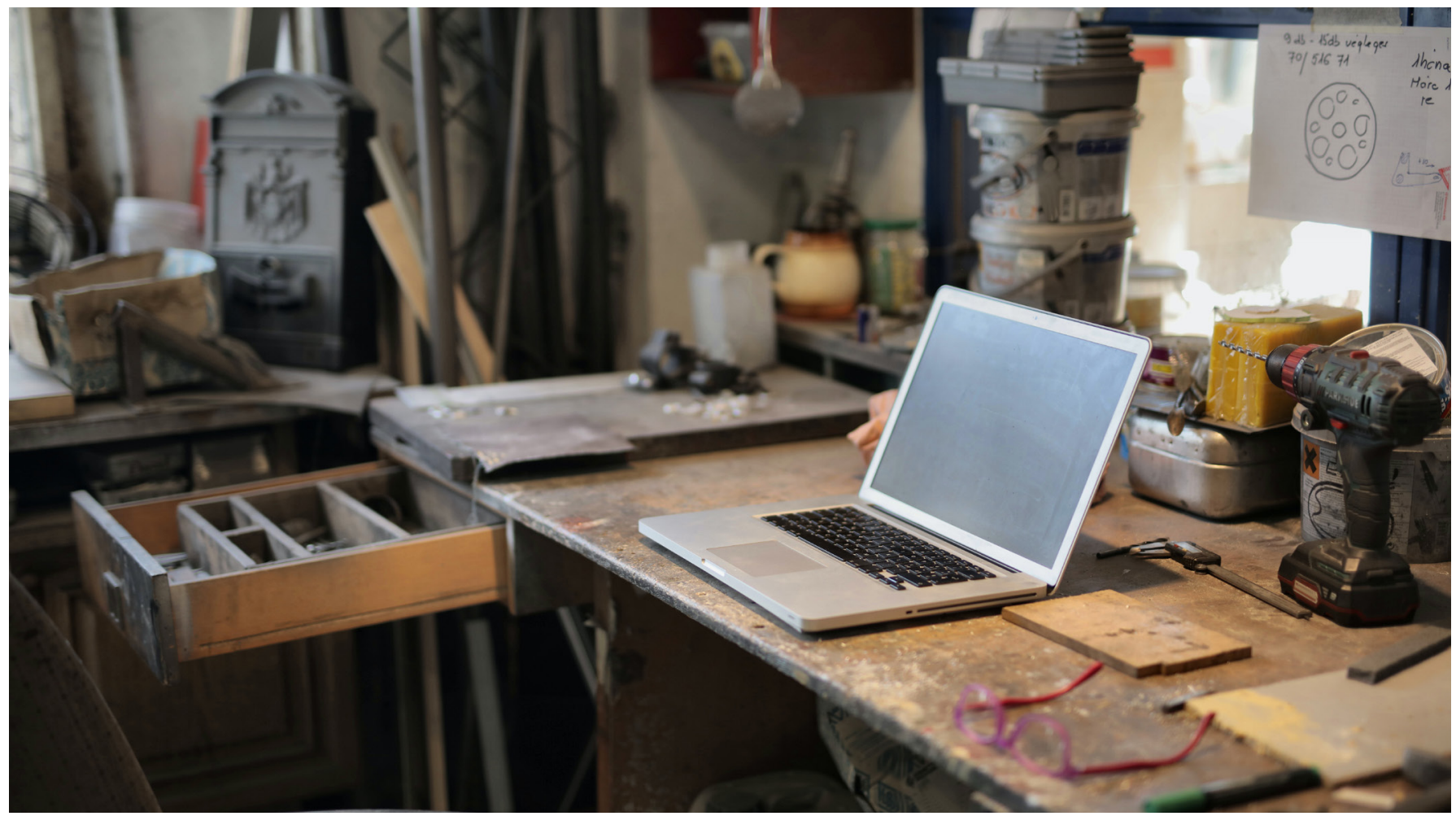

Laptop en la mesa del taller | foto Andrea Piacquadio

"el progreso no es necesario ni continuo; procede por saltos, o, como dirían los biólogos, por mutaciones. Estos saltos no consisten en llegar cada vez más lejos en la misma dirección; van acompañados de cambios de orientación, un poco al modo del caballo del ajedrez, que siempre tiene a su disposición varias progresiones, pero nunca en el peldaño de una escalera. (...) Lo que se gana con uno siempre se corre el riesgo de perderlo con otro, y sólo de vez en cuando es acumulativa la historia, es decir, los cambios se suman para formar una combinación favorable" (Lévi-Strauss 1993, 24-25).

Se trata de conseguir que el sistema actual "coevolucione" adaptándose a las exigencias ecológicas, como habría ocurrido durante buena parte de la historia de la humanidad (Naredo 2006). Estudiar un modelo constructivo que permita una nueva concepción orientada a reconstruir la ligazón con las culturas locales, dar espacio para la fusión y mezcla de sistemas posindustriales con las técnicas históricas locales ligadas al territorio y, por lo tanto, de menor consumo energético.

El concepto principal que se pretende es la permanencia, entendida más allá de la simple durabilidad de los materiales o sistemas, sino también su reproducción a lo largo del tiempo ya que no pone en peligro la estabilidad del medio físico y social. Significa reorientar la ciencia y la tecnología hacia lo permanente en todas las esferas que intervienen.

Esto exige la identificación y análisis de los elementos y técnicas constructivas utilizados por las comunidades locales en la construcción del patrimonio existente en aras de su readaptación a las actuales condiciones de la tardomodernidad.

El hecho de que la globalización del mercado haya desencadenado problemas muy parecidos en los dis- 
tintos territorios no significa que para dichos problemas sólo existan soluciones únicas. Consistiría en "pensar y actuar glocalmente", rechazando el paradigma eurocéntrico que prioriza lo global sobre lo local, lo general y abstracto sobre lo concreto y específico.

Se trata de analizar los sistemas constructivos tradicionales locales que son de baja tecnología y bajo consumo energético por antonomasia para identificar de qué modo se pueden adaptar a los requisitos de la actual sociedad altamente tecnificada, apoyados mediante normativas que, actualmente, no contemplan la reintroducción de sistemas tradicionales.

Aunque desde la enseñanza de la arquitectura también se hace necesario un replanteamiento, ya que los abordajes de los temarios suelen ser universalistas tal como la burocratización de las instituciones educativas exige. La introducción de conocimientos locales podría crear mucha discordancia al generar más variedad de la que se sería capaz de soportar, con un exceso de diversidad que dificultaría la capacidad de gestión (Díaz de Rada 2008). Por lo tanto, el reto de proporcionar una respuesta a los problemas medioambientales exige, desde la enseñanza, un desplazamiento de los contenidos a los códigos y de los códigos a los procesos cognitivos (Velasco, García y Díaz de Rada 1993) que asegure que arquitectos y arquitectas puedan plantear soluciones constructivas ligadas a cada lugar mediante la "reproposición" de técnicas tradicionales apoyados en la base suministrada por el pasado y, de este modo, contribuir a una reducción en la emisión de $\mathrm{CO}_{2}$ desde el campo arquitectónico.

\section{BIBLIOGRAFÍA}

- Díaz de Rada, A. (2008) ¿Qué obstáculos encuentra la etnografía cuando se practica en las instituciones escolares?. En: Jociles, M.I. y Franzé, A. (ed.) ¿Es la escuela el problema? Perspectivas socio-antropológicas de etnografía y educación. Madrid: Trotta editorial

- Foer, J.S. (2019) We are the weather: Saving the planet begins at breakfast. Reino Unido: Penguin
- Giddens, A. (2011) Consecuencias de la modernidad. Madrid: Alianza Editorial

- Laureano, P. (1999) Agua: el ciclo de la vida. Barcelona: Naciones Unidas; Agbar; CCD

- Lévi-Strauss, C. (1993) Raza y cultura. Madrid: Cátedra

- Naredo, J.M. (2006) Raíces económicas del deterioro ecológico y social: Más allá de los dogmas. Madrid: Siglo XXI

- Velasco, H., García, F.J. y Díaz de Rada, A. (1993) Introducción. En: Velasco, H., García, F.J. y Díaz de Rada, A. (ed.) Lecturas de antropología para educadores. El ámbito de la antropología de la educación y de la etnografía escolar. Madrid: Trotta, pp. 13-20 